\title{
2. Mapping early job insecurity impacts of the crisis in Europe
}

\section{Maria Karamessini, Maria Symeonaki, Dimitris Parsanoglou and Glykeria Stamatopoulou}

\section{INTRODUCTION}

The aim of this chapter is to provide a comprehensive cross-country analysis of early job insecurity (EJI) in Europe, comparing its present levels in different European countries with those that existed at the outbreak of the financial crisis in 2008. Job insecurity at the very beginning of a young person's professional career has numerous repercussions and a strong impact on the economy and society. It is therefore important to provide methodologies for measuring EJI as a first step towards better understanding the phenomenon and consequently proposing more effective policy responses.

When it comes to measuring EJI, different approaches have been proposed in the literature. These differences emanate to a certain extent from diverse definitions of EJI. In Karamessini et al. (2015) and in Dingeldey et al. (2015) an attempt was made to provide a definition of EJI and to connect the phenomenon with school-to-work transitions. Job insecurity relates to the overall concern of employees as to the continued existence of their job in the future. This 'concern', however, not only has a quantitative or static dimension pertaining to whether someone is or feels secure about keeping their job; it also includes a qualitative dimension that relates to 'insecurity about the continued existence of valued characteristics of the job' (Vander Elst et al., 2014). In fact such anxiety has been identified as one of the most important stressors in working life (De Witte, 1999). There is a discussion in the literature concerning the definition of job insecurity on the basis of its characteristics. Accordingly, job insecurity can be approached as a subjective experience and/or as an objective phenomenon. Subjective perceptions of job insecurity can involve components related to the individual's assessment of the probability of losing their job in the near future, where the affective component refers to the fear, worry or 
anxiety that one might actually lose one's job. In this chapter we perceive EJI as an objective phenomenon, with which different kinds of measurable indicators can be linked.

In measuring EJI, a special focus is put on school-to-work transitions in order to highlight the labour market situation of young people in Europe. There is a large volume of published studies describing methods for examining school-to-work transitions. These include sequence analysis, Markov systems, event history, optimal matching and cluster analysis (Alvarez et al., 2008; Betti et al., 2007; Bosch and Maloney, 2007; Brzinsky-Fay, 2007, 2014; Christodoulakis and Mamatzakis, 2009; Eurofound, 2014; Flek and Mysíková, 2015; Karamessini et al., 2016a, 2016b; McVicar and Anyadike-Danes, 2002; Scherer, 2001; Schoon et al., 2001; Symeonaki and Stamatopoulou, 2015; Symeonaki et al., forthcoming a, forthcoming b; Ward-Warmedinger and Macchiarelli, 2013).

The analysis we present in this chapter uses raw data drawn from the EU Labour Force Survey (EU-LFS) for the years 2008 (the beginning of the financial crisis) and 2015 (the most recent year for which data were available). It provides a better understanding of the level of EJI in European countries and of the differences between 2008 and 2015 with a view to ascertaining whether the crisis has brought convergence or divergence regarding EJI. More specifically, our ambition here is to contribute to the existing research and literature by developing a composite index of EJI based on 16 different indicators measured using raw data drawn from the EU-LFS. The measurement of EJI is not a straightforward process because 'perfect' indicators or definitions for EJI do not exist. However, various indicators, such as the unemployment rate or the NEET (not in employment, education or training) rate, have been used in the literature during recent decades and can serve as suitable tools for capturing certain traits of EJI. The indicators used here are linked with several domains relevant to objective and subjective characteristics of the labour market and of the labour condition of individuals. These indicators are considered to be complementary rather than competing and are combined into a single composite indicator to capture the degree of EJI in European countries.

It is clear that if one wanted to compare EJI across countries or study the evolution of EJI over time, it would be problematic to consider numerous indicators for different years simultaneously. Thus, there is a need to provide one single indicator for EJI that takes into account all possible indicators related to different domains of the phenomenon for which reliable and comparable data exist. This composite index will enable comparison of the labour market situation of young individuals in different European countries. To a similar end, Pusterla (2016) proposed a composite index for measuring the working conditions of youth in European 
countries. Here we attempt to specify a single, overall composite indicator of EJI for the first time. The results reveal the divergent impact of the crisis on unemployment and EJI and show that despite convergence in policies there is still significant divergence in EJI indicators between countries.

\section{METHODOLOGY}

In order to construct the EJI index, we use raw data drawn from the EU-LFS. More specifically, we use cross-sectional data for the years 2008 and 2015 covering the EU member states, as well as the EFTA countries Norway and Switzerland. The EU-LFS provides detailed information on labour market participation and working conditions and it allows for a multivariate analysis by sex, age, educational attainment and other sociodemographic characteristics, while common principles and guidelines are used to ensure cross-country comparability.

The focus in this study is on individuals aged between 15 and 29. A young person is commonly defined as aged 15-24, but for the purposes of the current analysis the upper limit is extended to 29 years for the following reasons: on the one hand, in some countries there would have been a far smaller sample to analyse, especially when measuring school-to-work transition probabilities; on the other hand, this extension allows us to capture more information on post-graduation employment experiences of young people who have completed tertiary education. Moreover, this broader age span is used in recognition of the fact that the school-to-work transition has been progressively delayed in many countries and is often completed after the mid-twenties. Evidently some young people remain in education beyond the age of 24 years (OECD, 1998: 91).

Some limitations arise due to differences in the national questionnaires used in the EU-LFS. Two of the important variables for our analysis are optional variables, ${ }^{1}$ and it is a decision for the national statistical authorities of each member state whether or not to include them in the main questionnaire. These variables are, therefore, not measured for a number of countries participating in the EU-LFS. ${ }^{2}$

The proposed indices provide a set of relative measures of EJI for countries across Europe based on different domains that refer to distinctive

MAINSTAT and WSTAT1Y.

2 For the year 2008 the variables are included for all member states except for Denmark, Germany, Ireland, Latvia, Malta, the Netherlands, Norway, Portugal, Switzerland and the United Kingdom. For the year 2015 they are not included for Germany, Ireland or the United Kingdom. 
traits of EJI. Each domain uses a set of indicators that can be measured using raw data drawn from the EU-LFS survey. Thus, the composite index combines information from these domains to produce an overall relative measure of EJI. The overall index scores (and those from each domain) can be used to rank each country according to the degree of EJI experienced by their young individuals.

The first domain is that of labour market outcomes, which focuses on a central aspect of EJI, namely the participation of youth in the labour market. In this dimension we consider common indicators regularly linked to job insecurity, such as the threat of unemployment and long-term unemployment. A common denominator of the ways in which employees perceive their situation as being insecure is the quality of their job, whereas empirically perceived insecurity is usually connected with objective conditions, such as employment statuses (Bernhardt and Krause, 2013; Klandermans et al., 2010). Thus, the second domain, Quality of jobs, includes indicators such as temporary and part-time employment. In the literature EJI is often studied by measuring school-to-work transitions (e.g., Brzinsky-Fay, 2014; Eurofound, 2014; Flek and Mysíková, 2015). In this respect we take into account the school-to-labour-market transition of youth by estimating the transition probabilities from school to employment, to unemployment and to inactivity. Within this stream we estimate the respective probabilities that form the Transition to labour market domain. Equally important for a young individual to feel (in)secure is the ability to find and the probability of finding and of keeping a job, which together form the Employment (in) security domain. The final domain focuses on data that can provide information concerning relative unemployment indicators such as youth versus adult and low- versus high-skills unemployment. These provide significant evidence on how age and education are related to unemployment.

The stages for the development of the composite index are the following:

1. Domains of EJI are identified.

2. Indicators that provide the best possible measure of each domain of EJI are chosen.

3. Indicators are estimated using raw data from the EU-LFS survey.

4. Indicators are standardized.

5. Reverse-scored indicators are recoded.

6. Correlation analysis to finalize indicators is performed.

7. Indicators with (equal) weight for each domain are combined.

8. Domain scores are ranked.

9. The overall index is estimated by combining domain scores using (equal) domain weights.

10. Member states are sorted according to the overall Index of EJI. 
The first condition in considering an indicator for a domain is its measurability. Indicators that can be problematic in their measurement because, for example, they are not statistically robust or are not comparable, cannot be included in the analysis. Moreover, indicators need to be domain-specific; that is, as far as possible they must be direct measures of that specific form of EJI. Other conditions are their ability to reflect the labour market situation and that of ranking their values, meaning that there should be no ambiguity as to whether high values of the indicator signify high or low degrees of EJI. A major advantage of using the EU-LFS data is that there are available indicators to consider in a consistent form, which allows for comparisons between countries. The aim is to obtain a single measure of EJI that is straightforward to interpret. Countries with a missing value on any indicator are excluded from the analysis.

\subsection{The Labour Market Outcomes Domain}

The indicators that fall within this domain are typical indicators used for the measurement of EJI. These are the youth participation rate (YPR), the youth employment rate (YER), the youth unemployment rate (YUR), the youth unemployment ratio (YURatio), the long-term unemployment rate (LTU) and the NEET rate. Figure 2.1 provides the values of YUR for the years 2008 and 2015 for each country. ${ }^{3}$ There is a clear difference between countries when the impact of the financial crisis on labour market outcomes is considered. There are countries that exhibit an increase in

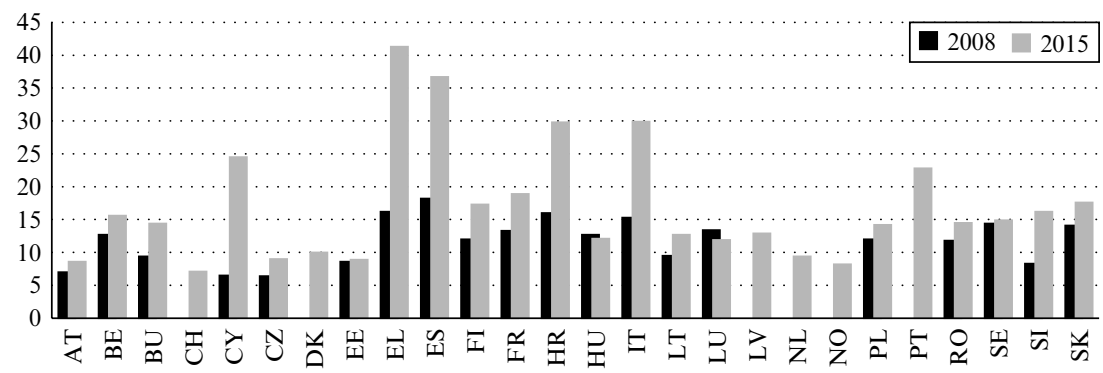

Source: Data taken from the EU Labour Force Survey (EU-LFS) for the years 2008 and 2015.

Figure 2.1 Youth unemployment rates, EU-LFS data, 2008 and 2015, ages 15-29

3 The values of YPR, YER, YURatio, LTU and the NEET rates for 2008 and 2015 for all countries are provided in the Appendix to this chapter. 
YPR and YER, such as Sweden and Lithuania, while others present a tremendous decrease in these indicators and a simultaneous increase in YUR and NEET rates. In the Southern European countries, for example, the impact of the crisis is severe and the differences are remarkable (YER for Greece, 2008: 42.9 per cent; 2015: 28.0 per cent; YER for Spain, 2008: 52.3 per cent; 2015: 33.7 per cent; YER for Italy, 2008: 39.1 per cent; 2015: 28.6 per cent; YER for Portugal, 2008: 50.9 per cent; 2015: 39.5 per cent). In 2015 Greece shows a YUR for individuals aged 15-29 equal to 41.3 per cent - close to the estimate for the employment rate in many countries and an LTU equal to 26.6 per cent, which is by far the highest amongst the countries studied here. Countries with inclusive labour markets present an LTU approximately equal to 1 per cent (in 2015, LTU for Norway: 1.1 per cent; LTU for Austria, Luxembourg and Finland: 1.6 per cent; LTU for Denmark: 1.4 per cent; and LTU for Switzerland: 1.5 per cent).

\subsection{The Quality of Jobs Domain}

In this category we gather information concerning the quality of jobs of young individuals. This can be achieved by measuring the incidence of temporary employment, the incidence of part-time employment and the incidence of involuntary part-time work. The latter is also important because part-time employment is not necessarily a matter of personal choice. Besides, relevant literature has shown that involuntary part-time work has been reaching significant dimensions in the United States (Doogan, 2009; Tilly, 1996), while in Europe country differentiations are very important: although the majority of part-time work within the EU is diachronically described by its workers as voluntary (14.2 per cent of part-time workers were working part time involuntarily in the EU in 1992, rising to 19.1 per cent in 1997 and falling back to 14.4 per cent in 2001): In Greece 44 per cent of part-time workers reported working involuntarily in 2001, compared to only 2.3 per cent in the Netherlands (Buddelmeyer et al., 2005: 286).

Figure 2.2 presents the incidence of part-time employment for each country for the years 2008 and 2015.4 In general there is great country differentiation. Temporary employment in 2015 shows huge variability, ranging from 3.2 per cent (Romania) to 55.1 per cent (Spain). Most of the transitional/post-socialist countries exhibit very low values of temporary employment and low percentages of part-time employment. The Southern European countries, on the other hand, present very high values of involuntary part-time employment, with Italy exhibiting the highest value

\footnotetext{
4 Temporary and part-time employment are presented in the Appendix to this chapter.
} 


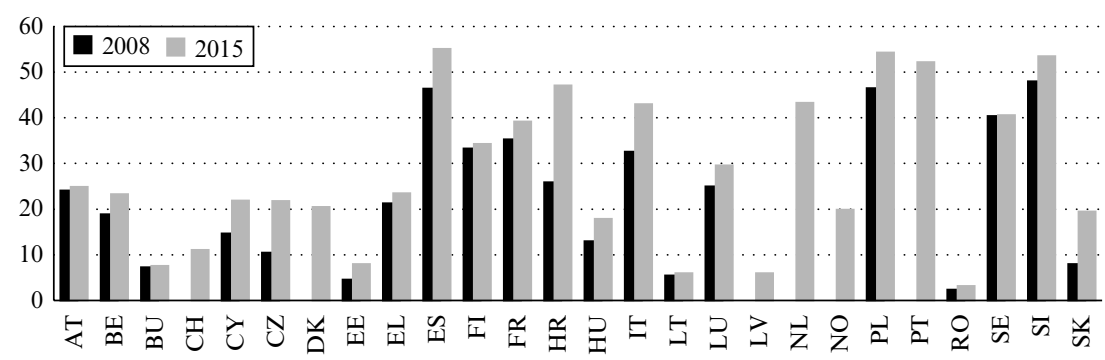

Source: Data taken from the EU Labour Force Survey (EU-LFS) for the years 2008 and 2015.

Figure 2.2 Incidence of temporary employment, EU-LFS data, 2008 and 2015 , ages $15-29$

of 82.2 per cent in 2015. It is worth mentioning that involuntary part-time employment showed a rapid increase during the crisis for the majority of Southern Europe.

\subsection{The Transitions from School to Work Domain}

Another crucial domain of EJI is related to the transition of young individuals from school (education or training) to the labour market. Young people who face unemployment or a slow transition may experience long-term adverse effects in terms of future labour market success, earnings, family formation and general life planning (Hellevik and Settersten, 2013), and also well-being (Schulenberg and Schoon, 2012). This may in turn jeopardize public and private investment in their education and training, which results in a loss for society as a whole. This is particularly true in the context of demographic challenges, which put added pressure on Europe's increasingly diminishing younger populations to integrate quickly and effectively into the labour market. ${ }^{5}$ In this respect we consider as important indicators of EJI the probability of an individual who has concluded education or training entering one of three labour market states - employment (school-to-employment transition probability, StE), unemployment (school-to-unemployment transition probability, StU) and inactivity (school-to-inactivity transition probability, StI). More specifically, in the EU-LFS survey respondents are asked about their 'current labour market state at the time of the survey'

5 http://ec.europa.eu/eurostat/statistics-explained/index.php/Being_young_in_Europe_ today_-_labour_market_-_access_and_participation (accessed 15 May 2018). 
(MAINSTAT) and their 'situation with regard to activity one year before the survey' (WSTAT1Y). The eight categories amongst which the respondents can choose for these variables are the following:

- Carries out a job or profession, including unpaid work for a family business or holding, including an apprenticeship or paid traineeship, etc.;

- Unemployed;

- Pupil, student, further training, unpaid work experience;

- In retirement or early retirement or has given up business;

- Permanently disabled;

- In compulsory military service;

- Fulfilling domestic tasks;

- Other inactive person.

Once the categories are recoded into the three states of employment, unemployment and inactivity, the indicators reflecting the school-toemployment, -unemployment and -inactivity transitions can be estimated as transition probabilities. In 2008 the school-to-work transition probabilities varied between 0.339 (Greece) and 0.755 (Czech Republic). In 2015 the values of the respective probabilities created a wider range, from 0.209 (Greece) to 0.778 (Switzerland), indicating that the crisis brought further divergence. Moreover, there are significant differences in the school-to-unemployment probabilities (Figure 2.3) in 2015, ranging from 0.069 in Switzerland to 0.637 in Croatia. In many countries there is a substantial decrease in the StE probabilities. In Spain, for example, the

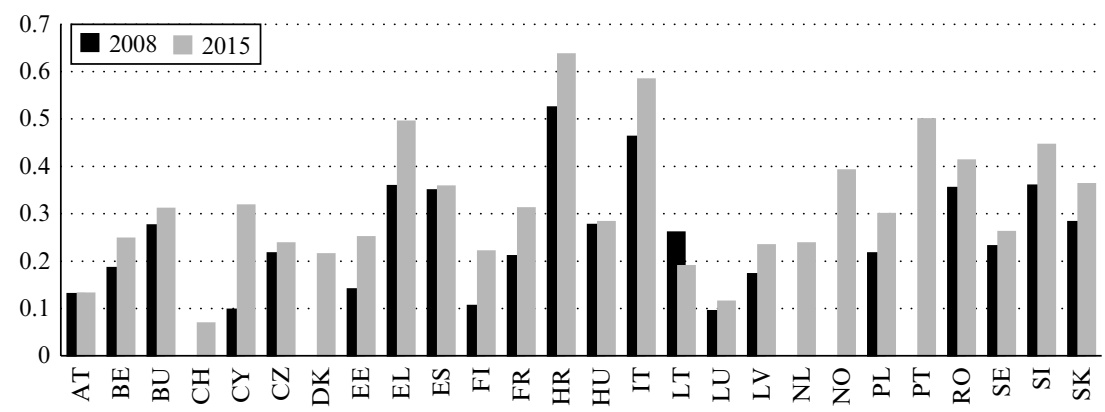

Source: Data taken from the EU Labour Force Survey (EU-LFS) for the years 2008 and 2015.

Figure 2.3 School-to-unemployment probabilities, EU-LFS data, 2008 and 2015 


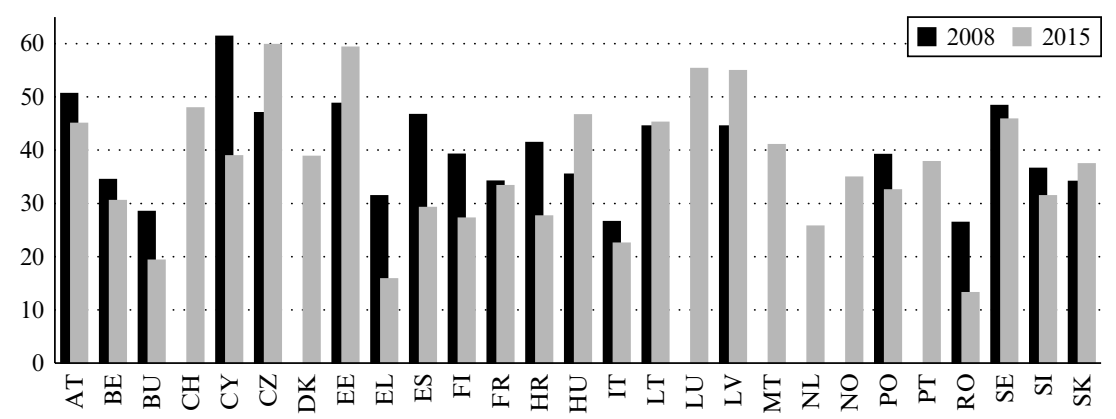

Source: Data taken from the EU Labour Force Survey (EU-LFS) for the years 2008 and 2015.

Figure 2.4 Job-finding rates, EU-LFS data, 2008 and 2015

probability dropped from 0.569 to 0.250 , and it fell in Cyprus from 0.458 to 0.269 , whereas in Lithuania and Hungary the respective probabilities increased, and in other countries, such as Austria and Sweden, they remained approximately at the same levels.

\subsection{The Employment (In)Security Domain}

Two key indicators for capturing employment (in)security are the jobfinding rate and the job-separation rate. Figure 2.4 displays the job-finding rates for all countries with available data for the years 2008 and 2015. The situation evidently changed considerably during the years of the crisis. The range of the job-separation rates became narrower, whereas the range of the job-finding rates became broader.

\subsection{The Relative Changes in Unemployment Rates Domain}

In this last dimension of EJI we distinguish two indicators regarding relative changes in unemployment rates. These are the youth-to-adult unemployment ratio (Y/AUR) and the relative unemployment rate of those individuals with low skills to those individuals with high skills (ULS/UHS), which provides evidence of how education and training influence unemployment. Low-skilled individuals correspond to those who have completed up to lower-secondary education (i.e., ISCED $<3$ in the International Standard Classification of Education). The variable used (HATLEV) corresponds to the highest educational attainment. When HATLEV $=1$ the highest educational attainment is less than primary, primary or lower secondary (ISCED 


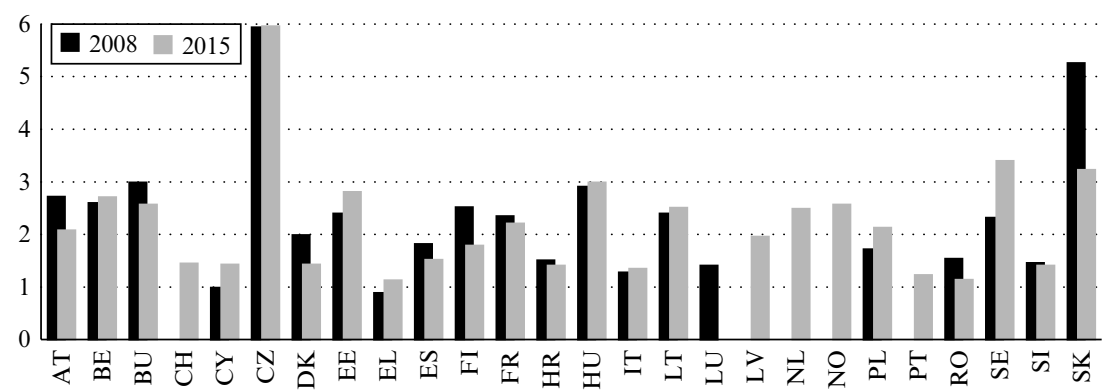

Source: Data taken from the EU Labour Force Survey (EU-LFS) for the years 2008 and 2015.

Figure 2.5 Relative unemployment rate (low skills vs high skills), EU-LFS data, 2008 and 2015

levels $0-2$ ), whereas when HATLEV $=2$ or 3 the individual has completed a medium level of education (upper-secondary and post-secondary nontertiary (ISCED levels 3 and 4) or a high level of education (short-cycle tertiary, bachelor or equivalent, master or equivalent, or doctoral or equivalent (ISCED levels 5-8).

Differences are evident in the relative changes in unemployment rates. In 2015 the unemployment rate of young individuals with lower education (ISCED $<3$ ) is approximately six times higher than that of individuals with a medium- or higher-level education in the Czech Republic, three times higher in Germany and 3.4 times higher in Sweden (Figure 2.5). In other countries the impact of education is not evident because the relative unemployment rate of low-skilled to higher-skilled individuals is approximately equal to 1 (1.13 for Greece and 1.14 for Romania). As far as the youth-to-adult unemployment ratio is concerned, it is worth mentioning that in some countries, such as Belgium, Croatia, Finland, Spain and the United Kingdom, there were no changes between 2008 and 2015.

\section{THE EJI INDEX}

In this section we define the overall Index of EJI and estimate its values for all European countries for which we have the necessary data (variables) for the years 2008 and 2015. As required by the theory on constructing composite indicators, we performed a correlation analysis, which led us to exclude the following indicators because of their low correlation with the rest: youth unemployment ratio, temporary employment, job-separation 
rate, youth-to-adult unemployment ratio, relative unemployment rate and school-to-inactivity transition probability.

'Positive' variables that need to be reversed in order for all variables to point in the same direction (since higher values of the indicator must correspond to higher degrees of EJI) are the youth participation rate, youth employment rate, school-to-employment transition probability and job-finding rate.

Each domain is constructed separately from the component indicators described in Sections 2.1 to 2.5 and each country is assigned a domain score and an EJI score. Therefore, the composite index can be defined as follows (Equation 2.1):

$$
E J I=\frac{\sum_{i=1}^{d} W_{d_{i}} \cdot \frac{\sum_{j=1}^{d_{i}} w_{i j} \cdot z \operatorname{zIn} d_{i j}}{\sum_{j=1}^{d_{i}} w_{i j}}}{\sum_{i=1}^{d} w_{d_{i}}}
$$

where $d$ is the number of domains (here $\mathrm{d}=4),{ }^{6} d_{i}$ is the number of indicators in the $\mathrm{i}$-th domain, $w_{i j}$ is the weight of the $\mathrm{j}$-th indicator in the $\mathrm{i}$-th domain, $z \operatorname{Ind}_{i j}$ is the weight of the i-th domain and $w_{d_{i}}$ is the $z$-score of the $\mathrm{j}$-th indicator in the $\mathrm{i}$-th domain.

Using Equation (2.1), we estimate the values of EJI in the countries examined. The domain scores for the countries are presented in Figure 2.6
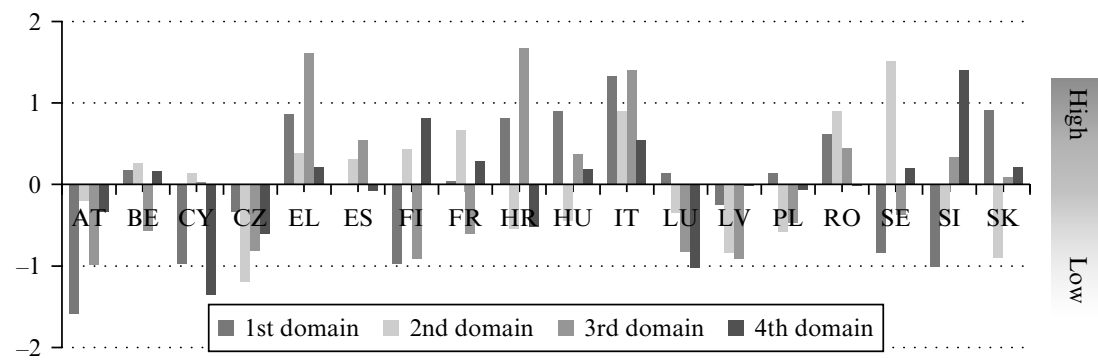

Source: Data taken from the EU Labour Force Survey (EU-LFS) for the years 2008 and 2015.

Figure 2.6 Domain scores for member states, EU-LFS data, 2008

6 The fifth domain was excluded on the basis of correlation analysis. 


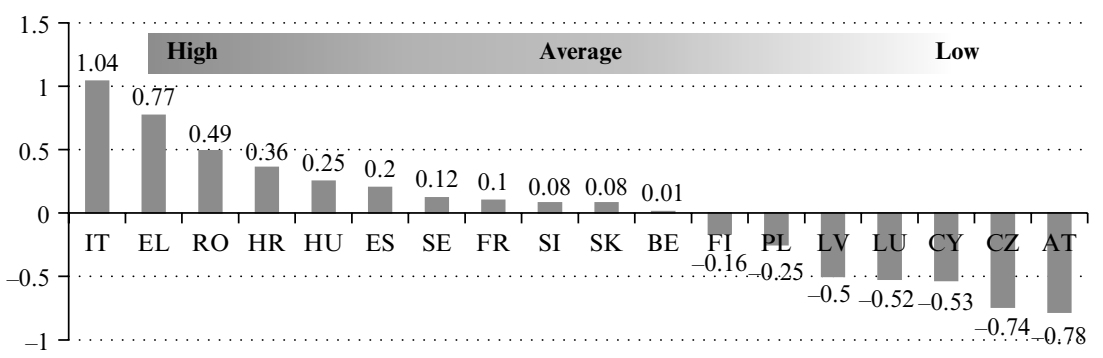

Source: Data taken from the EU Labour Force Survey (EU-LFS) for the years 2008 and 2015.

Figure 2.7 EJI scores for member states, EU-LFS data, 2008

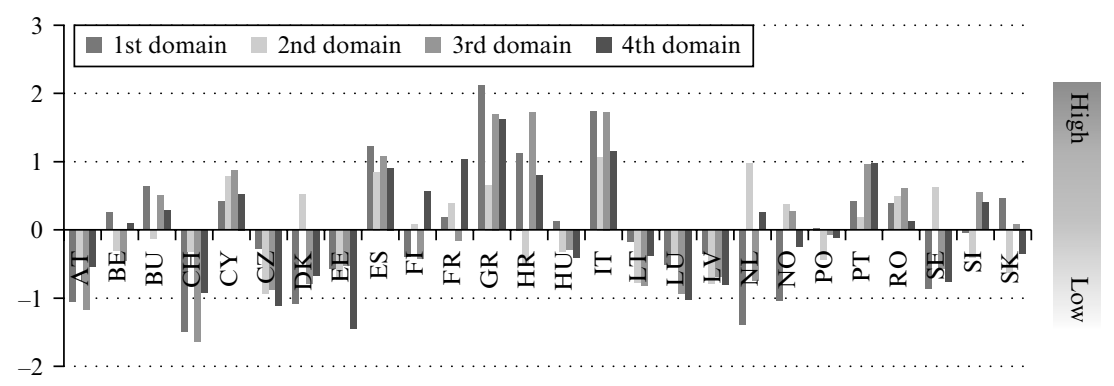

Source: Data taken from the EU Labour Force Survey (EU-LFS) for the years 2008 and 2015.

Figure 2.8 Domain scores for member states, EU-LFS data, 2015

for the year 2008, while the EJI scores for the same year are given in Figure 2.7. In 2008 countries exhibiting positive EJI scores display higher EJI, with Italy, Greece, Romania and Croatia being in the weakest position. On the other hand, countries with negative scores show lower degrees of EJI, with the Czech Republic and Austria in the prime position.

The domain scores for the countries for the year 2015 are presented in Figure 2.8, while the EJI scores for the same year are given in Figure 2.9. Looking at the differences in the EJI scores across countries between 2008 and 2015, a number of comments can be made regarding both the situation in specific countries and the distance between countries. Regarding the former, one can see a clear distinction between countries with low and high EJI: the first category includes countries known for their inclusive labour markets, such as Austria, Switzerland, Luxembourg and the Netherlands, 


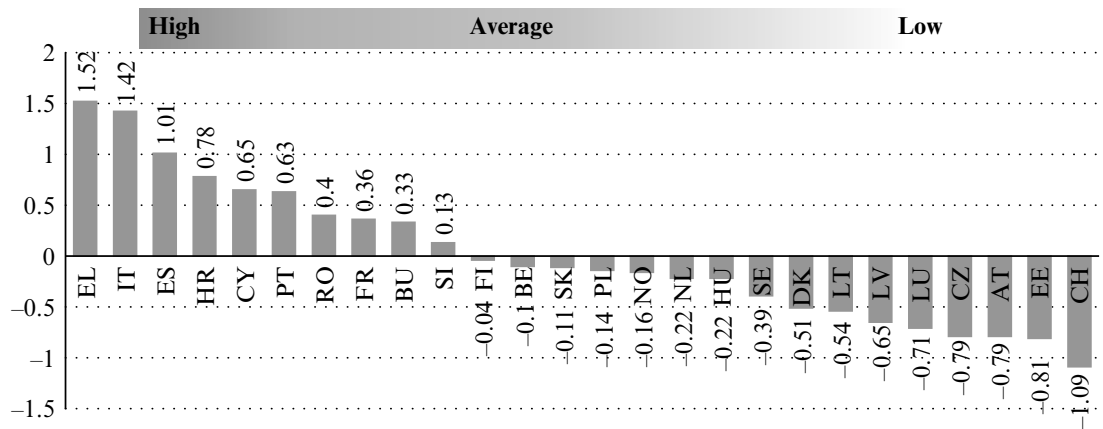

Source: Data taken from the EU Labour Force Survey (EU-LFS) for the years 2008 and 2015.

Figure 2.9 EJI scores for member states, EU-LFS data, 2015

but also the Czech Republic, Finland and Denmark; in the second category, Southern European countries are commonly found, notably Greece, Italy and Spain. Although we are unable to make direct comparisons between 2008 and 2015 (since the EJI index is a relative measure and the number of countries in the two periods differs), it is interesting to note that the gap between countries with low and high EJI has increased during the crisis.

Another significant aspect is the asymmetrical impact of the crisis. In certain countries characterized by low EJI the situation even improved during the crisis or deteriorated only slightly. On the contrary, in the countries figuring in the lowest ranks, early job insecurity increased, with Spain showing very sharp growth.

To emphasize the potentialities of the proposed multi-dimensional composite EJI index, we now provide an analysis limited to the participating countries in the NEGOTIATE project. Out of the 26 countries examined in 2015, Bulgaria was ranked in ninth position (with first place corresponding to the highest estimated degree of EJI). A closer look reveals that Bulgaria presents an imbalanced situation with regard to the four domains: in the field of quality of jobs, Bulgaria shows an encouraging score, mainly because of low percentages for part-time employment. This is counteracted by the adverse scores in all other domains.

Of the 18 countries studied in 2008, the Czech Republic is ranked second to last, which reveals low degrees of EJI. It presents positive scores in all domains, with better scores for quality of jobs and worse scores for labour market outcomes. The index presents a relatively constant picture in 2015, but with better scores in the relative changes in unemployment rates domain.

Greece is found in second position in 2008 , with particularly worrying 
scores for transition to the labour market. A difficulty in school-to-work transitions is what contributes most to the high degrees of EJI in Greece in 2008. Greece then climbs to first position in 2015; however, the dimension that contributes more to the high degrees of EJI is now the labour market outcomes domain. In fact the score in this domain is the worst across all the countries studied. On the other hand, quality of jobs is the domain that presents the lowest contribution to EJI in Greece in 2015.

Spain's scores show evidence of deterioration from 2008 to 2015. In 2008 two domain scores were positive, whereas in 2015 the situation of all domain scores worsened, pushing Spain from sixth position out of 18 countries in 2008 to third out of 26 countries in 2015, next to Greece and Italy.

In 2015 both Norway and Poland achieved similar EJI scores, but the way each domain contributes to the final EJI score is completely different. In Norway the labour market outcomes and the relative changes in the unemployment rates counterbalance the higher scores in the other two domains. In Poland all domain scores were rather low in both years.

Switzerland is the country exhibiting the lowest EJI score in 2015, with low scores in all domains and transition to the labour market being the domain contributing the most. Switzerland was second to last in 2008, with better scores in the quality of jobs domain.

\section{CONCLUSIONS}

In the context of growing job insecurity and systematic labour market and social exclusion of young people, research and policy have been attempting to examine the characteristics of the problem and to reach possible solutions. However, despite the growing discourses over the 'threat of a lost generation', accompanied by a multi-faceted social malaise that entails high risks of poverty, precarity, social exclusion, disaffection, insecurity, scarring, higher propensity towards offence and crime, as well as (mental and physical) health problems, the notion of 'EJI' is far from being completely theorized and conceptualized. In this chapter we attempted to provide for the first time a multi-dimensional composite index of EJI, based on a number of indicators measured using existing raw data drawn from the EU-LFS. The aim was to estimate and compare EJI in European countries before and during the crisis. The suggested index offers great potential for measuring and, most importantly, disentangling the degrees of EJI for each country, and also delivers evidence of the contribution of each domain to it.

It is obvious that EJI will differ across European countries. Countries with low EJI were identified (e.g., Switzerland, Denmark, Austria), as well as those with higher scores (Croatia, Italy, Spain and Greece are the 
countries with worrying levels of EJI). The analysis presented using this multi-dimensional approach highlights the different role played by the four EJI domains. Apart from significant divergence amongst European countries, what is also interesting is the asymmetrical effect of the financial crisis on each country. Even though all countries were affected to a certain degree at the beginning of the crisis, EJI seems to have much more significant repercussions in Greece, Italy and Spain, in other words, in countries where the youth unemployment rate has significantly increased in recent years. An important consequence of this increase in unemployment and EJI has been the growing mobility of young people from Southern Europe towards countries in Western and Northern Europe. In the case of Greece there have been considerable outflows of Greek citizens with a relatively high level of education: it is estimated (Lazaretou, 2016) that approximately 0.5 million high-skilled young Greeks left the country during the last years of the crisis. ${ }^{7}$ Similar trends have been identified in Spain. ${ }^{8}$

Our analysis provides evidence based on empirical data that early job insecurity is an important issue for labour markets in Europe, that it can be measured and that it must be tackled because it exhibits worrying trends in many European countries. Moreover, our methodology is able to remove some ambiguity regarding how the crisis affected different EU countries and can be used to identify nuanced ways in which relevant policies should be designed and implemented to address early job insecurity. To give a specific example, highlighting these kinds of differentiations can be useful for optimizing the design of Youth Guarantee programmes and their objectives, adapting them to specific national and social contexts. Similarly, our methods can provide insights for a better allocation of funding towards targeted and effective actions through the Youth Employment Initiative. In this way both the European Employment Strategy and the National Reform Programmes and Stability/Convergence Programmes can be informed and updated towards more comprehensive approaches that might provide effective responses to the complicated issues that arise from early job insecurity.

\section{REFERENCES}

Alvarez E, Ciocchini F and Konwar K (2008) A locally stationary Markov chain model for labour dynamics. Journal of Data Science 7: 27-42.

7 Lambrianidis (2011) suggests that this phenomenon is not new, that it was not generated but intensified by the crisis.

8 'Young Spaniards flock to Germany to escape economic misery back home' (Connolly, 2013). 
Bernhardt $\mathbf{J}$ and Krause A (2013) Flexibility, performance and perception of job security: A comparison of East and West German employees in standard employment relationships. Work, Employment and Society 28(2): 285-304.

Betti G, Lemmi A and Verma V (2007) A comparative analysis of school-to-work transitions in the European Union. Innovation: The European Journal of Social Science Research 18(4): 419-42.

Bosch M and Maloney W (2007) Comparative analysis of labor market dynamics using Markov processes: An application to informality. IZA Discussion Paper no. 3038. Bonn: Institute for the Study of Labor.

Brzinsky-Fay C (2007) Lost in transition? Labour market entry sequences of school leavers in Europe. European Sociological Review 23(4): 409-22.

Brzinsky-Fay C (2014) The measurement of school-to-work transitions as processes. About events and sequences. European Societies 16(2): 213-32.

Buddelmeyer H, Mourre G and Ward M (2005) Recent developments in part-time work in EU countries: Trends and policy. In: Gómez-Salvador R, Lamo A, Petrongolo B, Ward M and Wasmer E (eds) Labour Supply and Incentives to Work in Europe. Cheltenham, UK and Northampton, MA, USA: Edward Elgar Publishing, pp. 273-308.

Christodoulakis G and Mamatzakis C (2009) Labour market dynamics in EU: A Bayesian Markov chain approach. Discussion Paper no. 7. Thessaloniki: Department of Economics, University of Macedonia.

Connolly K (2013) Young Spaniards flock to Germany to escape economic misery back home. The Observer, 7 July. https://www.theguardian.com/world/2013/jul/07 /spanish-youth-germany-unemployment-crisis (accessed 10 January 2018).

De Witte H (1999) Job insecurity and psychological well-being: Review of the literature and exploration of some unresolved issues. European Journal of Work and Organizational Psychology 8(2): 155-77.

Dingeldey I, Hvinden B, Hyggen C, O'Reilly J and Schoyen MA (2015) Understanding the consequences of early job insecurity and labour market exclusion: The interaction of structural conditions, institutions, active agency and capability. NEGOTIATE Working Paper no. 2.1. https://negotiate-research.eu/files/2015/04/NEGOTIATEworking-paper-no-D2.1-1.pdf (accessed 15 June 2018).

Doogan K (2009) New Capitalism? The Transformation of Work. Cambridge, UK: Polity Press.

Eurofound (2014) Mapping Youth Transitions in Europe. Luxembourg: Publications Office of the European Union.

Flek V and Mysíková M (2015) Unemployment dynamics in Central Europe: A labour flow approach. Prague Economic Papers 24(1): 73-87.

Hellevik T and Settersten RA Jr (2013) Life planning among young adults in 23 European countries: The effects of individual and country security. European Sociological Review 29(5): 923-38.

Karamessini M, Papazachariou A, Parsanoglou D and Stamatopoulou G (2015) Indicators and data sources to measure patterns of labour market entry across countries. NEGOTIATE Working Paper no. 3.1. https://negotiate-research.eu/ files/2015/04/NEGOTIAE-working-paper-no-D3.1.pdf (accessed 15 June 2018).

Karamessini M, Symeonaki M and Stamatopoulou G (2016a) The role of the economic crisis in determining the degree of early job insecurity in Europe. NEGOTIATE Working Paper no. 3.3. https://negotiate-research.eu/files/2015/04/ NEGOTIATE-working-paper-D3.3.pdf (accessed 15 June 2018).

Karamessini M, Symeonaki M, Stamatopoulou G and Papazachariou A (2016b) 
The careers of young people in Europe during the economic crisis: Identifying risk factors. NEGOTIATE Working Paper no. 3.2. https://negotiate-research.eu/ files/2015/04/NEGOTIATE-working-paper-no-D3.2-The-careers-of-young-peo ple-in-Eurpa-during-the-economic-crisis.pdf (accessed 15 June 2018).

Klandermans B, Hesselink JK and Van Vuuren T (2010) Employment status and job insecurity: On the subjective appraisal of an objective status. Economic and Industrial Democracy 31(4): 557-77.

Lambrianidis L (2011) Investing in Flight: Brain Drain from Greece in the

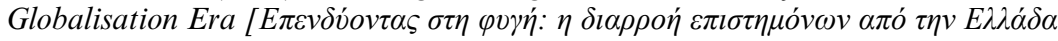

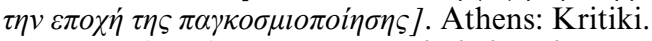

Lazaretou S (2016) Human Capital Flight: The Contemporary Emigration Tendency

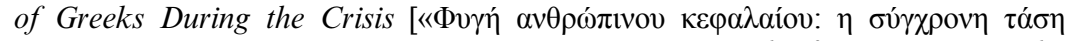

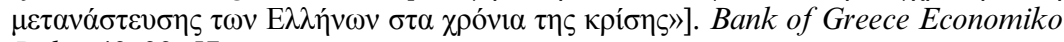
Deltio 43: 33-57.

McVicar D and Anyadike-Danes M (2002) Predicting successful and unsuccessful transitions from school to work by using sequence methods. Journal of the Royal Statistical Society: Series A (Statistics in Society) 165(2): 317-34.

OECD (1998) Getting started, settling in: the transition from education to the labour market, OECD Employment Outlook. Paris: OECD.

Pusterla F (2016) The Great Recession and the working conditions of youth: A descriptive analysis of the European labour market. KOF Studies no 83. Zürich: Swiss Economic Institute.

Scherer S (2001) Early career patterns: A comparison of Great Britain and West Germany. European Sociological Review 17(2): 119-44.

Schoon I, McCulloch A, Joshi HE, Wiggins RD and Bynner J (2001) Transitions from school to work in a changing social context. Young 9: 4-22.

Schulenberg J and Schoon I (2012) The transition to adulthood across time and space: Overview of special section: Transition to adulthood in the UK, the US and Finland. Longitudinal and Life Course Studies 3(2): 164-72.

Symeonaki M, Karamessini M and Stamatopoulou G (forthcoming a) Genderbased differences on the impact of the economic crisis on labour market flows in Southern Europe. In: Bozeman J and Skiadas C (eds) Data Analysis and Applications: New and Classical Approaches. London: ISTE Science Publishing.

Symeonaki M, Karamessini M and Stamatopoulou G (forthcoming b) Measuring school-to-work transition probabilities in Europe with evidence from the EU-SILC. In: Bozeman J and Skiadas C (eds) Data Analysis and Applications: New and Classical Approaches. London: ISTE Science Publishing.

Symeonaki M and Stamatopoulou G (2015) A Markov system analysis application on labour market dynamics: The case of Greece. In: 36th Annual Conference of the International Working Party on Labour Market Segmentation (IWPLMS), Athens, Greece, 22-24 June.

Tilly C (1996) Half a Job: Bad and Good Part-time Jobs in a Changing Labor Market. Philadelphia, PA: Temple University Press.

Vander Elst T, De Witte H and De Cuyper N (2014) The job insecurity scale: A psychometric evaluation across five European countries. European Journal of Work and Organizational Psychology 23(3): 364-80.

Ward-Warmedinger M and Macchiarelli C (2013) Transitions in labour market status in the European Union. LEQS Paper no. 69. London: London School of Economics. 


\section{APPENDIX}

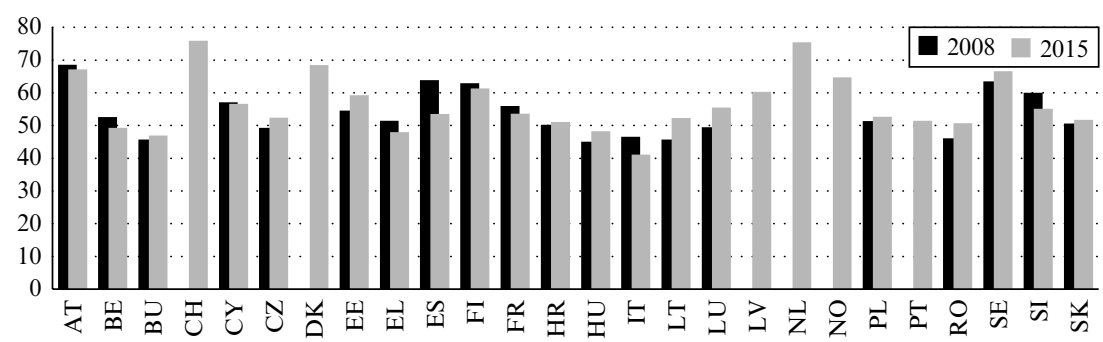

Figure 2A.1 Youth participation rates, EU-LFS data, 2008 and 2015, ages 15-29

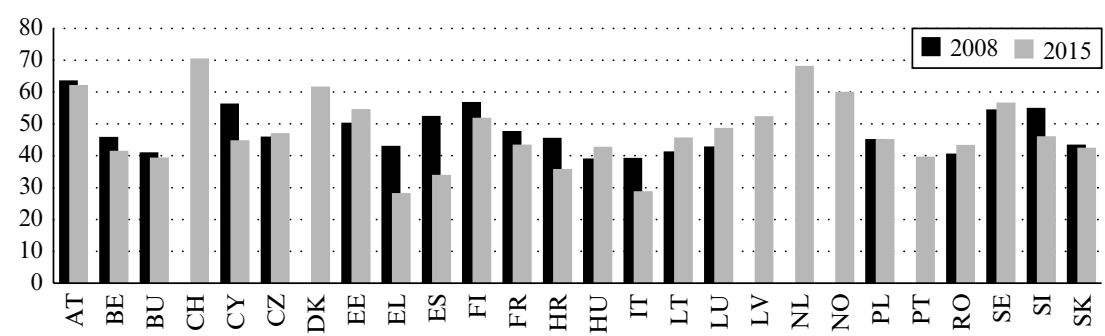

Figure 2A.2 Youth employment rates, EU-LFS data, 2008 and 2015, ages 15-29

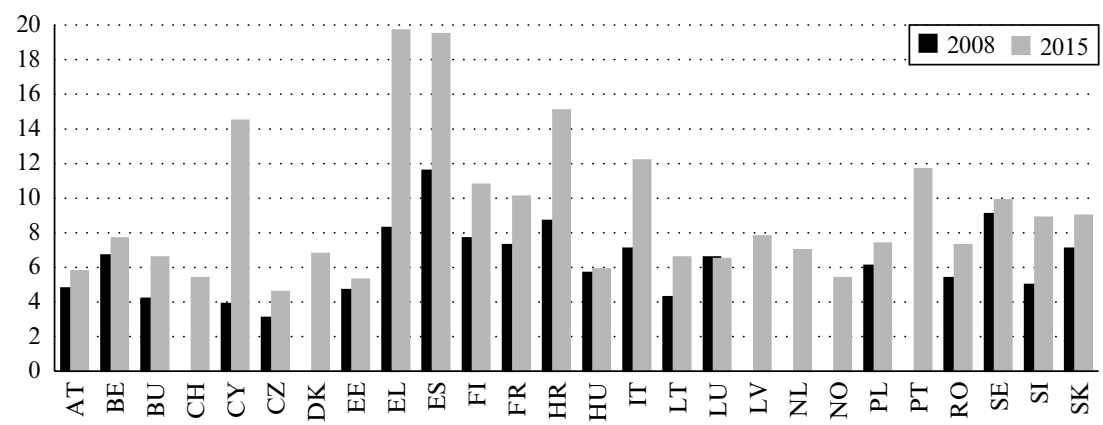

Figure 2A.3 Youth unemployment ratio, EU-LFS data, 2008 and 2015, ages 15-29 


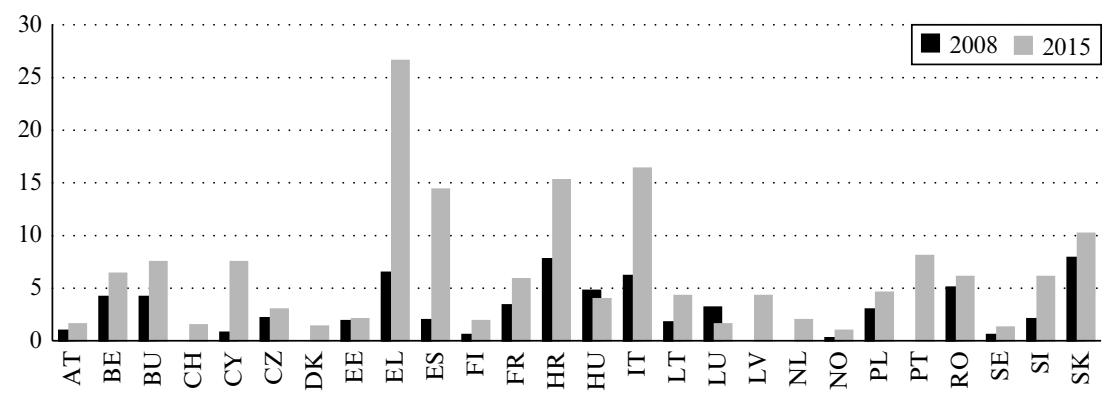

Figure 2A.4 Long-term unemployment, EU-LFS data, 2008 and 2015, ages 15-29

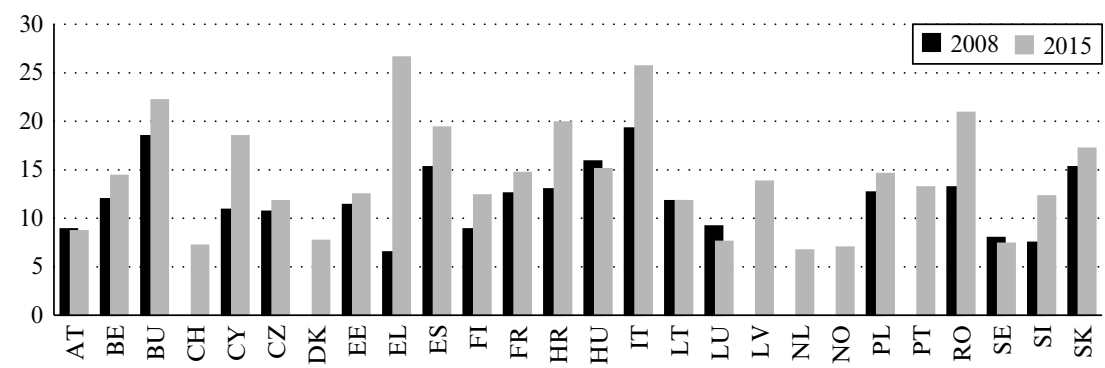

Figure 2A.5 NEET rates, EU-LFS data, 2008 and 2015, ages 15-29

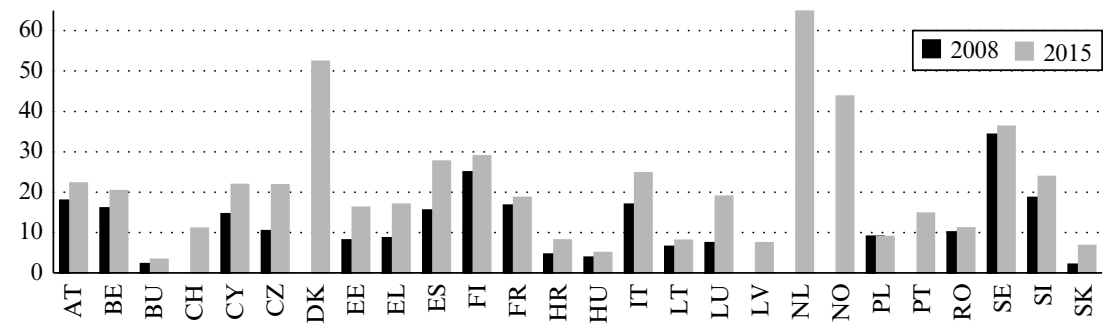

Figure 2A.6 Incidence of part-time employment, EU-LFS data, 2008 and 2015, ages 15-29 


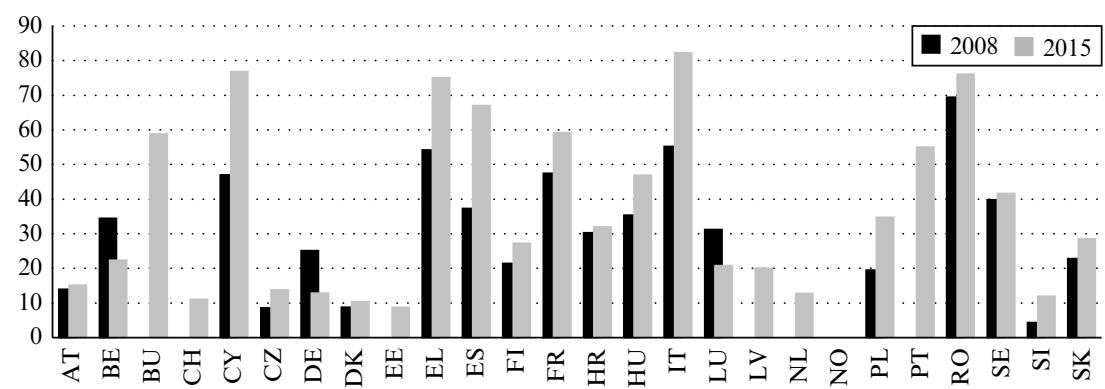

Figure 2A.7 Incidence of involuntary part-time employment, EU-LFS data, 2008 and 2015, ages 15-29

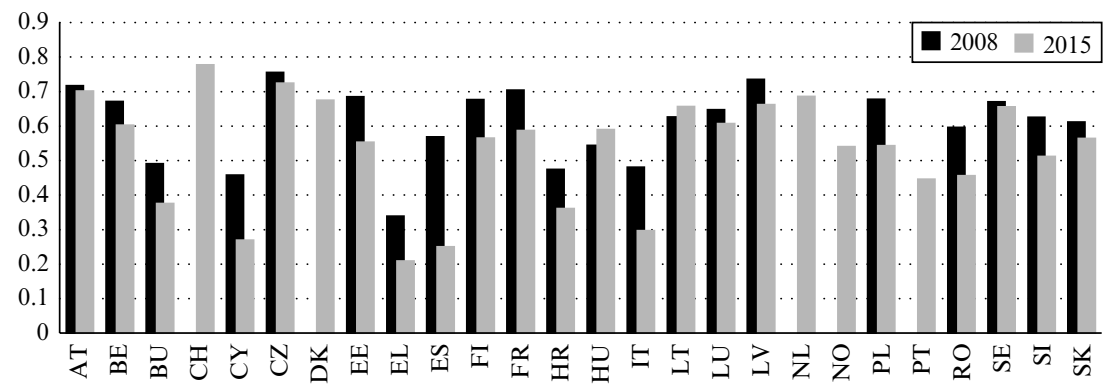

Figure 2A.8 School-to-employment probabilities, EU-LFS data, 2008 and 2015

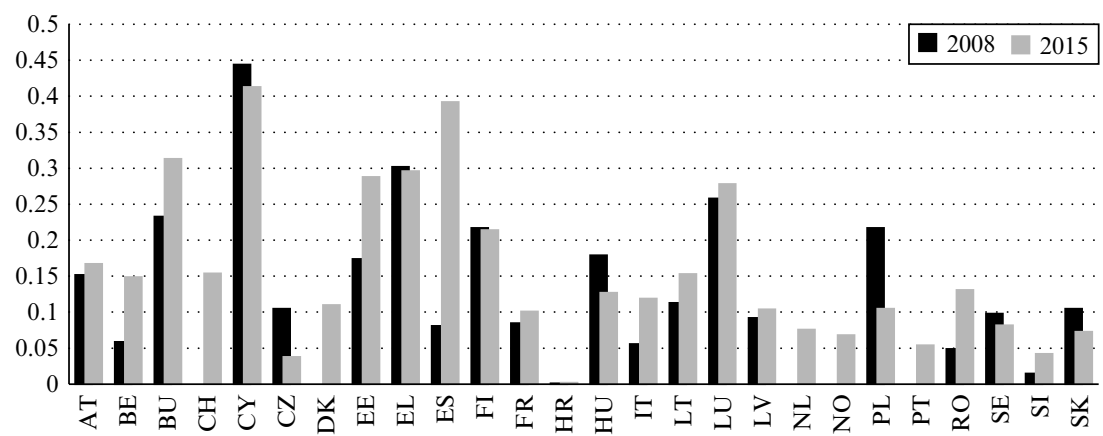

Figure 2 A.9 School-to-inactivity probabilities, EU-LFS data, 2008 and 2015 


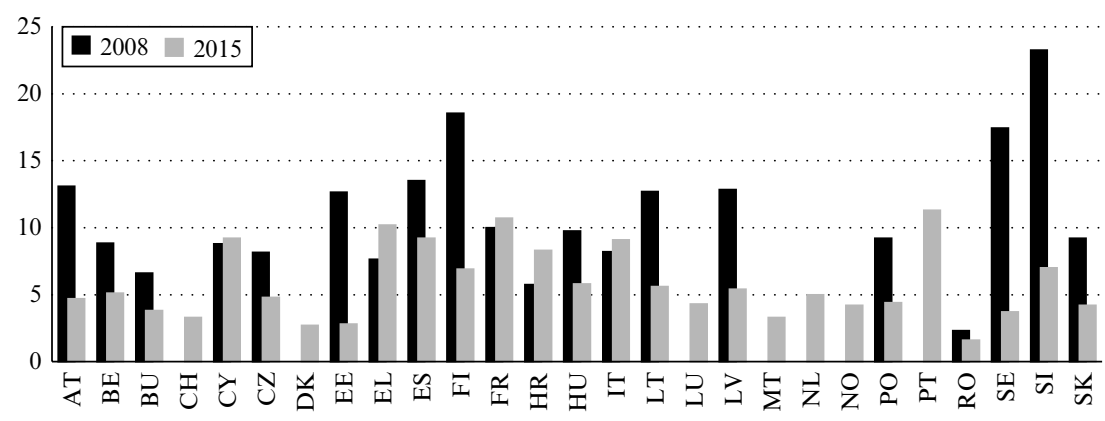

Figure 2A.10 Job separation rates, EU-LFS data, 2008 and 2015

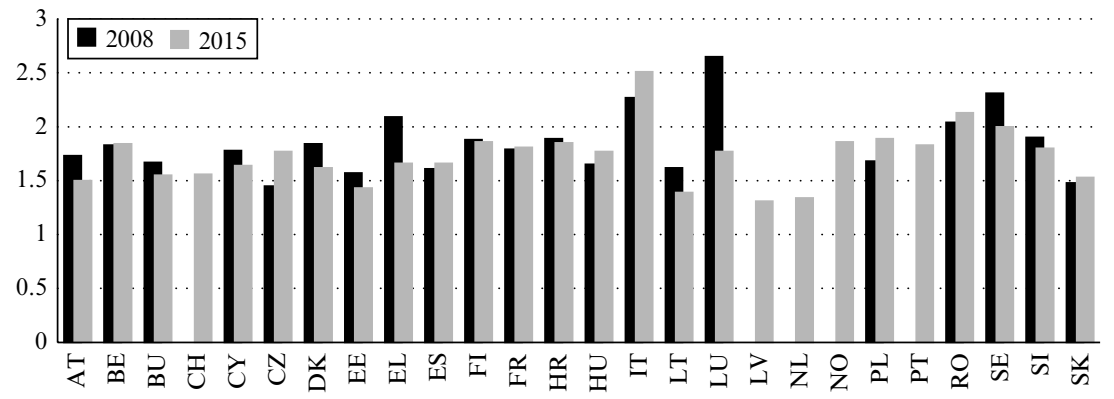

Figure 2A.11 Youth-to-adult unemployment ratio, EU-LFS data, 2008 and 2015 